Article

\title{
Mapping as Gap-Finder: Geddes, Tyrwhitt, and the Comparative Spatial Analysis of Port City Regions
}

\author{
Carola Hein * and Yvonne van Mil \\ Chair of History of Architecture and Urban Planning, Faculty of Architecture \& The Built Environment, TU Delft, \\ 2628BL Delft, The Netherlands; E-Mails: c.m.hein@tudelft.nl (C.H.), y.b.c.vanmil@tudelft.nl (Y.v.M.) \\ * Corresponding author
}

Submitted: 15 January 2020 | Accepted: 13 April 2020 | Published: 30 June 2020

\begin{abstract}
Politicians, planners, and mapmakers have long used mapping to depict selected spaces, to document natural and humanmade changes within them, and to identify spaces where planning intervention is needed or can be helpful. Recent innovations involving big data, GIS-based research and digital datasets offer opportunities for maps and mapping that can lead to a better understanding of the interrelation of spatial, social, and cultural elements over time and to facilitate planning. A close analysis of the historic transformation of the built environment (such as land use, land ownership, infrastructures), the development of institutional structures (municipal boundaries) and the narrative that accompanies them (as embedded in maps and plans) through historical geo-spatial mapping can facilitate the identification of 'gaps,' where spatial, institutional, or cultural opportunities and challenges exist and where planning can be useful. Such an understanding can provide novel insights into the conditions and complexity of multiple transitions (energy, digital, technological) and provide a better foundation for future design. Our use of geo-spatial mapping to identify 'gaps' builds upon the work of Patrick Geddes and Jacqueline Tyrwhitt, who promoted the concept of survey-before-plan. As Tyrwhitt argued in 1950, the consistent overlaying of information can help us see patterns and outliers and derive meaning from huge, complex territories and large amounts of data (Tyrwhitt, 1950b). We can then better identify planning opportunities. Following an analysis of mapping as an analytical tool, we explore questions of sources, time, representation, and scale in the use of mapping at a time of increased availability of data. This article represents an initial effort to analyze the role of mapping as a tool of understanding, communicating, and ultimately planning through the lens of port city regions and their development over time. As a first step, it proposes conducting observations of historical geospatial mapping in port city regions in Europe: the Nieuwe Waterweg in the Netherlands, the Thames in the UK, and the Elbe in Germany. Probing the challenges and opportunities presented by historical sources, questions of representation and scale and data layers, the article concludes by proposing historical geo-spatial maps and mapping as a tool of display and comparative research and as a 'gap finder.'
\end{abstract}

\section{Keywords}

comparative spatial analyses; gap-finder; GIS; historical geo-spatial mapping; port city regions; survey-before-plan

\section{Issue}

This article is part of the issue "Territories in Time: Mapping Palimpsest Horizons" edited by Chiara Cavalieri (UCLouvain, Belgium) and Elena Cogato Lanza (EPFL, Switzerland).

(C) 2020 by the authors; licensee Cogitatio (Lisbon, Portugal). This article is licensed under a Creative Commons Attribution 4.0 International License (CC BY).

\section{Introduction}

Maps and mapping allow public and private stakeholders to understand spatial contexts, environmental changes, institutional settings, and cultural implications and to make informed decisions about future planning. Recent innovations involving big data, GIS-based research, and digital datasets offer new opportunities to use maps and mapping to gain a better understanding of spatial and cultural elements. They can facilitate interventions at a time of multiple transitions (energy, digital, technological) and provide a better foundation for future design. 
Taking into account the new opportunities provided by GIS and digital datasets, this article proposes first steps towards a methodology that connects spatial and social mapping to gain a better understanding of economic, political, social, and cultural processes in port city regions at times of transition and to provide a foundation for contemporary planning. We posit that mapping can be used as a 'gap-finder' to provide insights into technological as well as socio-cultural development spurred by new technology and to identify opportunities and challenges for future (planning) interventions.

Few geo-spatial tools or research methods are designed to analyze and represent the palimpsest of spaces, social interactions, and cultural practices of cities and the evolution of particular processes over time. It is possible to access a great variety of maps and plans, written documents, and diverse visuals that document aspects of particular spaces and the social patterns of cities. A methodology is needed that complements quantitative assessments of economic and logistic aspects of a particular area and enables the analysis of spatial and cultural patterns (Hein \& van Mil, 2019). Geo-spatial mapping can produce a better understanding of the historic transformations of urban settlements and their spatial, social, and cultural entanglements. Historical geo-spatial mapping can help us understand how people have changed cities and institutions over time and in conjunction with complex economic, political, social, and cultural transformations. It can serve as a methodology for transdisciplinary research helping spatial, social, and humanities scholars to consider both quantitative and qualitative aspects of life and work in a spatial context and it can serve planners and policy makers.

Although many planners have used mapping as a research method and have taken regional approaches, the proposed methodology is still in an early stage of development. This article first examines the power of maps and the shifting application of mapping as a tool for communication and understanding spaces. It argues that there is a long tradition that we can build upon. The use of mapping as a means to overlay different research approaches and to create a palimpsest of knowledge refers notably to the concept of surveybefore-plan, an idea that was expounded a century ago by Patrick Geddes (Batey, 2018). This concept was further refined by Jacqueline Tyrwhitt in the 1950s and ever since it has continued to influence how plans are made. Following Geddes and Tyrwhitt, we raise questions about the appropriate scale of surveys and mapping and propose a scale that encompasses all relevant phenomena and that is not limited by administrative boundaries. With the increasing amount of digital data and the use of digital mapping techniques, surveybefore-plan has taken on new meaning and promise. GIS, digital archives and datasets, Google Earth, Google Street View, and similar technologies provide many new possibilities to study and map large amounts of (spatial) data, at zoomable scales.
Historical socio-spatial mapping can be used to study any type of human settlement. We focus here on port city regions, which are paradigms of territories where complex global flows intersect. Many coastal cities worldwide still need to develop adaptation policies (Olazabal, Ruiz de Gopegui, Tompkins, Venner, \& Smith, 2019) that are aligned with local conditions. Such planning requires coordination among stakeholders, including port authorities, city and regional governments, private and public actors, as well as NGOs and citizens. Effective plans will require a solid foundation and the identification of common values or a shared port city culture. International port city institutions, such as the AIVP (www.aivp.org/en) and RETE (http://retedigital.com/en), have long pleaded for the consideration of spatial and cultural factors in the analysis of port cities. To understand the challenges facing ports and cities today, we have to look beyond the physical and institutional borders of a port or a city or the challenges that occur on the border between them (often called the port-city interface; see also Hein \& van Mil, 2019).

The economic development of ports and cities has always depended on their ability to reach into the foreland and hinterland. To understand processes of port and city growth and the interaction between ports and cities through the ages, we have to examine ports and cities at the scale in which they operate, here loosely called the region. For our pilot study, we have chosen three port city regions on which we have already worked and for which we have sufficient data. The port city region of the Western Netherlands, around the port of Rotterdam, serves as an example of the challenges and opportunities that large port city regions face world-wide. In our current area of investigation, Hamburg and London provide examples of other planning challenges for port city regions of past, present, and future. Each of these three case studies shows different historical interactions between port and city in the larger region. In our conclusion, we argue that historical geo-spatial mapping on different scales can facilitate transdisciplinary research and help bring lessons from the past to the attention of planners.

\section{Mapping as a Historical Tool for Understanding, Communicating, and Designing}

Knowledge is power, and mapping is a powerful tool for understanding landscapes and territories, spatial objects, and social relationships. Maps are select two-dimensional representations, defined in the Encyclopedia Britannica as "a graphic representation, drawn to scale and usually on a flat surface, of featuresfor example, geographical, geological, or geopoliticalof an area of the Earth or of any other celestial body" (Fuechsel, n.d.). Politicians, policy makers, and planners have used maps (and mapmakers) to extract and refine knowledge, to understand the physicality of the surface of the earth and man-made spaces and to prepare for military interventions. They have employed maps as pro- 
paganda and they have used them to find routes over land and sea. Maps have served as foundations for new plans, urban designs, and other interventions. Cities in the Greek, Roman, and Chinese empires were built according to plans. Some landscapes, like those in the Netherlands, are largely man-made. Historic maps provide us with important insights on how decision makers of the past have conceptualized space. Digitized private and public map collections and geo-spatial tools have therefore gained importance for research and planning.

Mapping requires definitions of scale, time, and perspective. While this may be obvious, it is important to carefully conceptualize these elements as they can result in different planning approaches. Select types of mapping make it possible to explore neighborhoods, cities, land parts, or the course of rivers with different degrees of precision. The scale of mapping has usually been related directly to the realm of the commissioner of the map: Municipal leaders focused on their city and immediate territories, kings and nation-states would focus on their national realm. The interest of the commissioner also determined the availability of data and the scale of intervention. Just as the choice of a specific scale relates to the theme and narrative that the map-maker chooses, so does the selection of time or the choice of a theme.
To serve a multitude of stakeholders and to facilitate exchange, it is important to make careful decisions regarding scale, time, and detail of representation. These decisions must acknowledge a more mundane challenge that impacts mapping decisions: The usually rectangular proportions of the paper (or other material) on which the organic forms of natural and humanmade spaces have been mapped impact the way in which maps transmit information (see Figure 1). Even in digital format, when zooming is possible, rectangular screens shape the perspective of the viewer. These decisions also have to acknowledge the variable reliability of maps. As Mark Monmonier (1996/2014) claims, maps lie because the choices that cartographers make-consciously or unconsciously-mean that a map is far from objective. To estimate the reliability of a map, it is important to know the function: Who is the cartographer or client and what was the purpose of the map? A map is first and foremost a tool of communication, and to understand a map we need to know both the supply side (the maker and client) and the demand side. We can only understand maps if we know what the cartographer wanted to show, to whom, and why. The purpose of the map determines the scale, the reliability, implementation, and content (Renes, 2016).
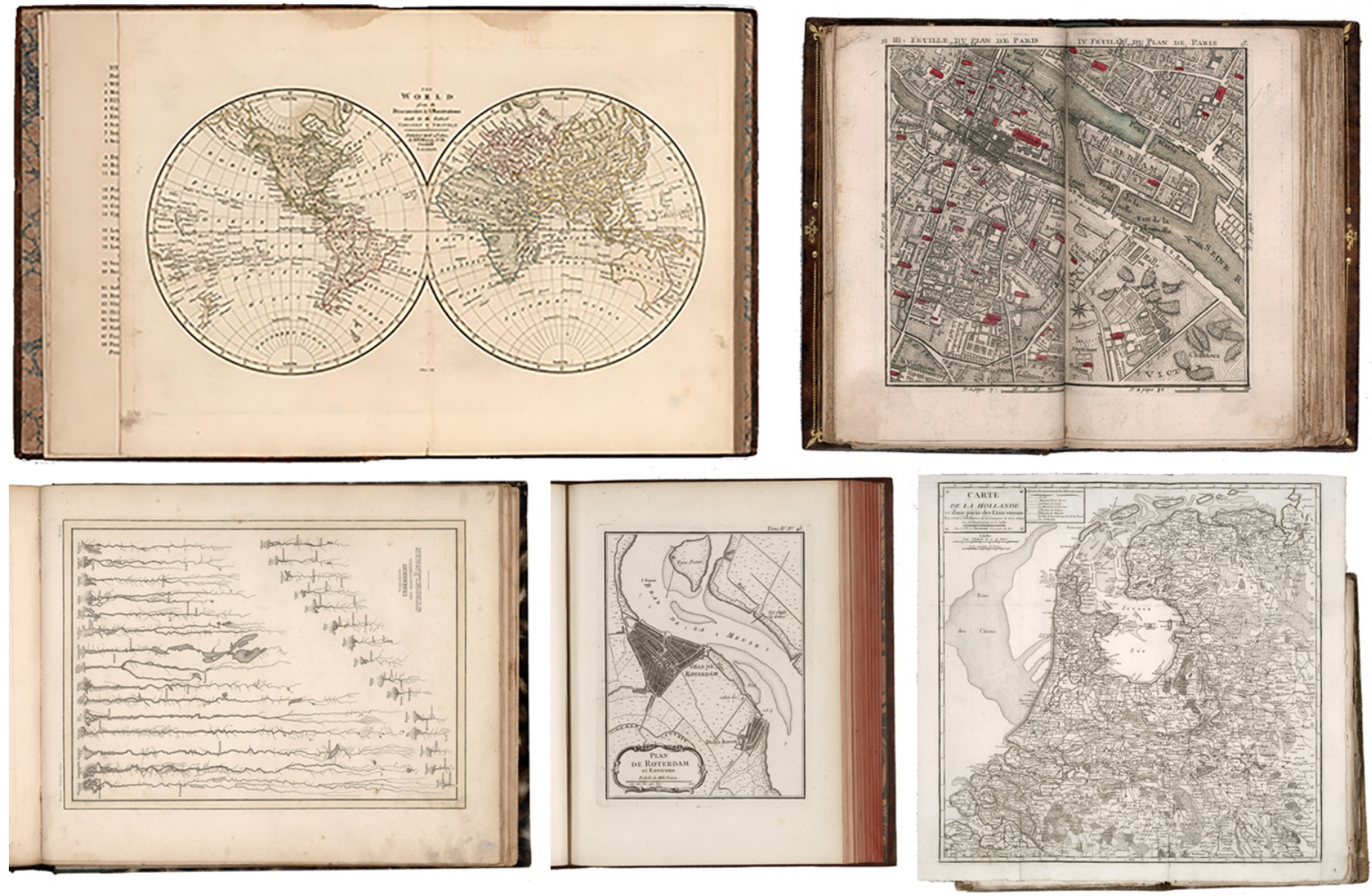

Figure 1. Examples of old maps. Top, from left to right: The World from the Discoveries \& Observations Made in the Latest Voyages \& Travels (Wilkinson, 1809); Ille. Feuille du Plan de Paris. IVe. Feuille du Plan de Paris (Denis \& Pasquier, 1765). Bottom, from left to right: Vergleichende Uebersicht der bedeutendsten Stromlängen (Meyer, 1852); Plan de Rotterdam et Environs (Bellin, 1764); Carte de la Hollande et d'une Partie des Etats Voisins: Volume 2 (Grimoard \& de Beaurain, 1672). 
To facilitate discussions among different stakeholders and to bring together different perspectives, we propose mapping at a scale that helps identify challenges and opportunities in the fuzzy territories of overlapping spaces and institutions (Hein, 2019). Historical geospatial mapping can thus be used as what we call a 'gap-finder' - that is, as a tool to better understand transitional territories that often cross institutional boundaries without strong, mutually supportive governance frameworks, legal systems, and planning guidelines. The need for finding gaps has been recognized by other fields, such as traders and transit institutions as well as the Gapminder Foundation (www.gapminder.org); we apply it here to the fields of mapping and planning. We argue that the concept can enable the user to conceptualize spatial, institutional, or other boundaries imposed at a time when maps were only available as paper documents stored at local or national institutions. To understand and overcome choices made in the past in terms of scale, time, and perspective, it is important to think carefully about the continuities of conceptualization from historical maps to mapping using digitized historic data and interpretative geospatial analysis.

Opportunities for creating thematic, analytical maps of historic conditions have increased with digitization. Before the 19th century, map-makers mainly produced topographic and geographical maps. They tended to visualize forms on the surface of the earth as clearly and faithfully as possible. Only occasionally did they produce thematic maps, such as a map of yellow fever in New York published in 1790, one of the earliest experiments of social cartography (Vaughan, 2018). According to geographer and cartographer Arthur $\mathrm{H}$. Robinson, in contrast to a general map, a thematic map concentrates:

On showing the geographical occurrence and variation of a single phenomenon, or at most a very few. Instead of having as its primary function the display of the relative locations of a variety of different features, the pure thematic map focusses on the differences from place to place of one class of feature. The number of possible themes is nearly unlimited and ranges over the whole gamut of man's interest in the present and past physical, social, and economical world, from geology to religion, and from population to disease. (Robinson, 1982, p. 15)

Throughout the 19th century, cartographers used thematic maps to convey complex population statistics such as birth and death rates and on the spread of diseases and poverty within urban areas. Port cities were of particular interest because they were places where diseases were carried by ships and sites of rapid population growth, as exemplified by maps of London, New York, and Amsterdam, such as the Map Showing the Spread of Cholera and the Number of Deaths from this Disease in Each of the 50 Neighborhoods of Amsterdam, by Isaac Teixeira de Mattos (1866), and Sanitary \& Topographical
Map of the City and Island of New York, prepared for the Council of Hygiene and Public Health of the Citizens Association, under the direction of topographical engineer Egbert L. Viele (1865). In the Great Britain of the 19th century, the negative urban impacts of industrialization led to the emergence of social reformers who based their work on urban research. The social reformer Charles Booth produced street maps that revealed extreme contrasts of wealth and poverty in London (Figure 2). Fastgrowing cities became the focus of attention for planning, with maps and statistical data for surveying and tabulating the 'uncharted' territories within urban settlements serving as evidence for the need for improvement and the starting point for urban planning (Vaughan, 2018).

As urban planning became a profession in the late 19th and early 20th century, mapping as a way of studying urban regions emerged as a scientific discipline. It became a way to systematically combine spatial and social data and to uncover health issues, social problems, or land use challenges. These uses of mapping developed hand in hand with the professionalization of urban and spatial planning (Hein, 2018). The added value of mapping for planning was aptly described by architect Jack Whittle:

An important characteristic of a map is the facility it offers for locating, defining and describing some features of an area. By means of a map, fact (i.e., survey data) and ideas (or proposal for future use) can immediately related to the site they cover. Information, which in tabular form is not visually attached to any one piece of land, can be added to the map by using colors or symbols drawn on the appropriate part of the map, thus intergrading the information with the area involved. Map making, therefore, has become an indispensable part of planning technique. (Whittle, 1950, p. 540)

\section{Geospatial Mapping Based on Geddes and Tyrwhitt}

One of the most important developments for the application of mapping in urban planning was the introduction of survey-before-plan by Scottish biologist and pioneer of urban planning Patrick Geddes (1854-1932). Planners steadily improved their mapping methods and used maps for analysis and presentations. The 1950s saw the emergence of scientific principles of collecting and mapping data. In 1950, Tyrwhitt published her research and mapping method-based on Geddes' survey-before-plan-in the Association for Planning and Regional Reconstruction's (APRR) Town and Country Planning Textbook (see Tyrwhitt, 1950b). Here she introduced her overlaying technique, which became the foundation for the integrating and analytical capacities of geographical information systems (Nijhuis, 2015; Shoshkes, 2006, 2016).

Tyrwhitt was the first to describe the overlaying technique in an academic setting and two decades later 


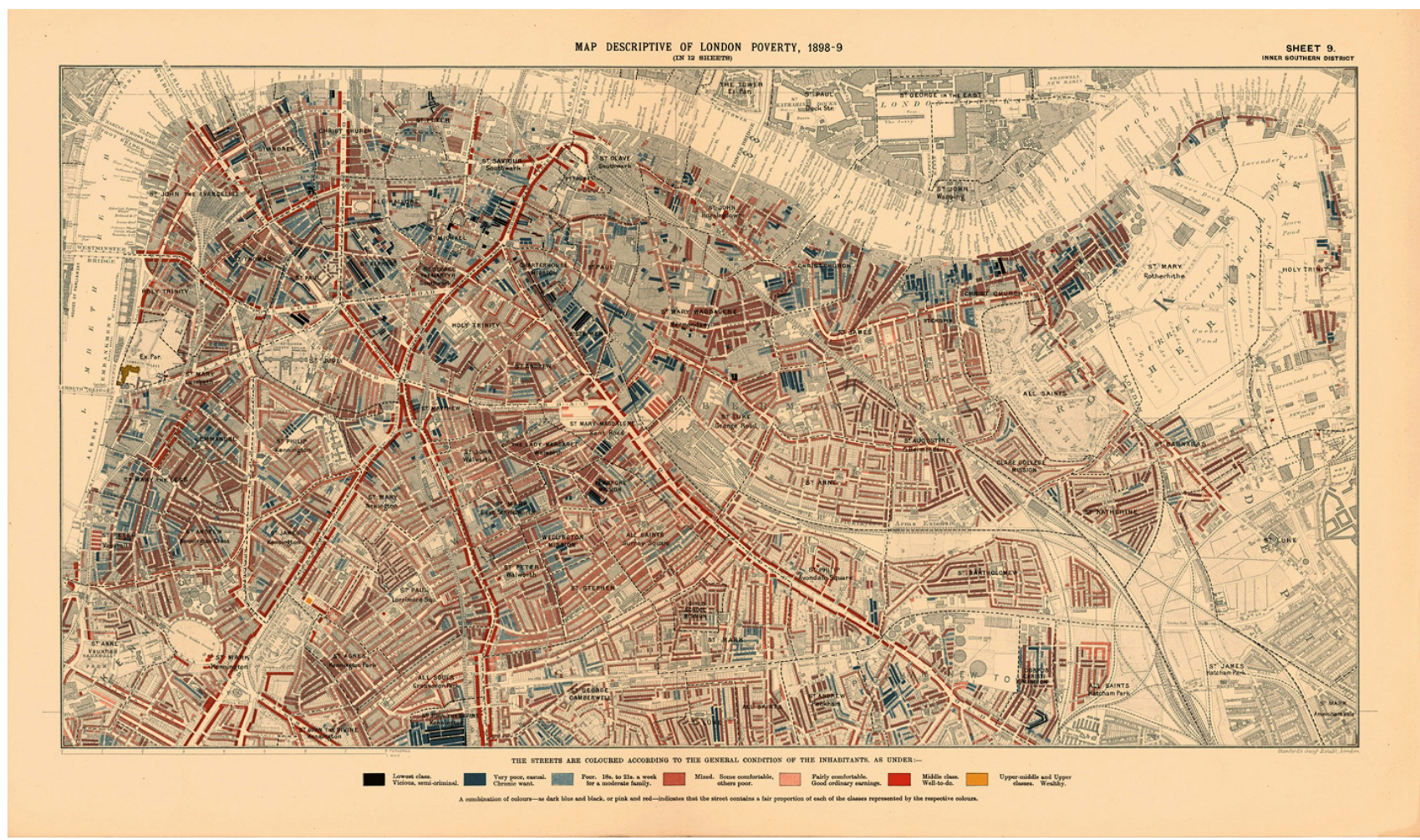

Figure 2. Example of a thematic map of poverty in south-east London: Map Descriptive of London Poverty, 1898-1899. Sheet 9. Inner Southern District (Booth, 1898). (C) 2016 London School of Economics and Political Science.

the technique became widely adopted in Britain and became a standard feature of the ecological planning method as taught and practiced in the Department of Landscape Architecture and Regional Planning at the University of Pennsylvania, in the United States, where Ian L. McHarg was Chairman (Nijhuis, 2015; Shoshkes, 2006). American landscape architects Philip H. Lewis and Ian McHarg applied it to a project in Delmarva in 1967. This was the first urban planning project which applied computer-generated maps, databases and digital overlaying techniques using a computer-based information system (Nijhuis, 2015). Tyrwhitt explained her method of conducting a planning survey based on Geddes' surveybefore-plan in the APRR textbook. As starting point of the survey, Tyrwhitt called for an overall view of the physical setting of the community, mapping the important natural and man-made features. She described "what to look at" (the geography and the use of land), "what to analyze" (the people, where people are and how they move around) and how to get a general appraisal of how the community makes its living and the character and quality of life. In addition, she explained which resources to explore for planning, including documentary material like maps, plans, reports, statistics, and other sources of information needed for making the survey (Tyrwhitt, 1950b, pp. 150-153). Tyrwhitt relied mainly on national sources such as Ordnance Survey maps, geological survey sheets, land utilization surveys, census reports on country volumes, and parish tables.

Tyrwhitt made a number of key statements that have inspired our proposal for using mapping as a 'gap-finder.'
She drew special attention to gaps in research data required for planning: "In some localities much of the preliminary planning will already have been done, and the problem will be to discover the gaps and achieve a balanced programme" (Tyrwhitt, 1950b, pp. 149, 177). We have built on this notion to create the term 'gapfinder.' She argued for a careful choice of the area of intervention, going beyond administrative borders. Tyrwhitt wrote:

From the first preliminary survey and analysis it should be possible to decide tentatively the physical area to be planned for. The limits of this area are not to be confused with the corporate limits of a central city; surrounding urban areas that appear to be tied economically and socially should be included. (Tyrwhitt, 1950b, pp. 153-154)

She emphasized that "generally the survey should not be restricted to the local administrative boundaries, which seldom express geographical or social realities" (Tyrwhitt, 1950b, p. 161). Using predetermined, often historical, administrative boundaries does not help us understand urban regions. Tyrwhitt did not define the concept of the region herself but quoted the 1942 statement of Spanish architect Jose Luis Sert:

Town and country merge into one another and are elements of what may be called a regional unit. Every city forms part of a geographical, economic, social, cultural and political region, upon which its development 
depends. Towns or cities cannot in consequence be studies apart from their region which constitute their natural limits and environment....The city should be examined in the economic ensemble of its region of influence. A plan of the economic unit, the 'city region' in its totality, must therefore replace the simple city plan of today. (Sert, 1944, pp. 246-249; Tyrwhitt, 1950a, p. 140)

Questions of scale and representation are addressed throughout the chapters in the textbook, each written by a specialist. In the district survey, Tyrwhitt introduces her method for making maps. She shows a series of twelve maps on a scale of 1:25.000 (Figure 3). Tyrwhitt uses a black and white presentation technique and transparent paper. She emphasizes that the whole series of maps must be drawn to the same scale, and on each map, she uses the river line as a general feature to act as guide, so that a viewer could readily relate places throughout the series (Tyrwhitt, 1950b, pp. 162-174). She writes:

As far as possible maps should be drawn on transparent paper, so that when completed the maps to the same scale can be 'sieved'-i.e., placed one on top of another in turn so that correlations or their absence can be noted. (Tyrwhitt, 1950b, p. 157)

Tyrwhitt did not discuss the choice of scale. Instead, the architect Jack Whittle provided three main considerations for choosing the right scale in his contribution to the Town and Country Planning Textbook. He argued that planners should: 1 ) use the smallest scale at which it is possible to illustrate clearly the problem or proposals involved; 2 ) choose the detail of the base map so that it relates in scale to the detail of the information to be mapped; and 3) not confuse the scale used for analyzing with those for presenting (Whittle, 1950, p. 544).
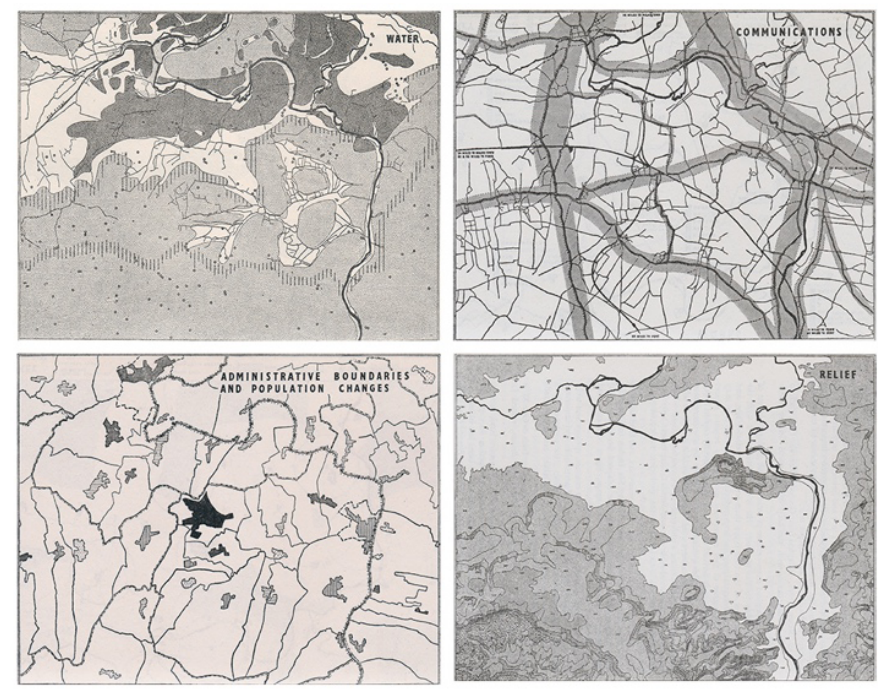

The use of these transparent thematic maps anticipates the introduction of GIS. GIS based geo-spatial mapping allows us to provide a standardized basis for comparison and to adapt both representation and scale. We are also building on the work of Steffen Nijhuis and Han Meyer, from TU Delft, who produced a GIS based analysis of urbanized delta regions that can be considered a research method for studying deltas around the world (Meyer \& Nijhuis, 2014), and we are building on existing comparative methodologies for analyzing port cities and port-city relationships (Andrade, Costa, \& Blasco López, 2020; Guo, Qin, Du, \& Han, 2020; Monios, Bergqvist, \& Woxenius, 2018; Schipper, Vreugdenhil, \& de Jong, 2017). To investigate and better understand the complex data of port city regions, we are proposing a research methodology based on historical geo-spatial mapping that brings Tyrwhitt's methods to the era of GIS and uses a shared method and shared definitions for scale, time, and perspective.

\section{Digitization in Mapping and Design}

Since the beginning of the 20th century, mapping has come to play an increasingly important role in the planning process, as evidenced by the APRR textbook where several chapters are dedicated to mapping and mapbased survey methods. The introduction of GIS in the 1970s facilitated the use of overlaying techniques as a method for evaluating landscape change and the future impact of planning alternatives (Nijhuis, 2015). However, despite the benefits geospatial mapping offers for understanding and planning, urban and planning historians who study such inherently spatial topics as migration, segregation, gentrification, and suburbanization tend to rely on historical maps, rather than using interpretative geo-spatial mapping, to illustrate their findings. They only occasionally use GIS as a research method for analyz-

Figure 3. Example used by Tyrwhitt to explain the overlaying technique as a tool for research. Thematic maps on water, communications (infrastructure), administrative boundaries, population changes, etc., resulting in a synthesis map pointing out the characteristics of the landscape. Source: Tyrwhitt (1950b). 
ing spatial patterns (Hillier, 2010). More explicit attention to the spatial nature of social and cultural topics and their interaction through the use of GIS based historical mapping can provide a better foundation for planners who need to understand the forces that have shaped cities and landscapes before they propose new interventions (Figure 4).

According to Professor of Digital Humanities Ian Gregory and human geographer Alistair Geddes, there are four main advantages to using GIS in historical research: 1) GIS structures data that allows them to be discovered and explored in ways that are explicitly spatial; 2) it allows data to be visualized using mapping and other approaches; 3 ) it allows the data to be analyzed in ways that are explicitly spatial; and 4) has the ability to integrate data from a wide range of apparently incompatible sources (Gregory \& Geddes, 2014). In addition to the four benefits that Gregory and Geddes mention, GIS allows researchers to compare various data on multiple scale levels. Some prominent examples of the benefits of geospatial historic mapping exist, notably, the work of the American historian David Bodenhamer, who popularized the concept of deep maps as a way for humanists to take full advantage of the spatial dimension of the discipline (Bodenhamer, Harris, \& Corrigan, 2015). Deep maps-a term coined by William Least Heat-Moon in 1991-are detailed representations of a place and the people, buildings, objects, flora, and fauna that are present there and part of the activities of daily life. To make such maps, we have to carefully reflect on issues of representation and scale.

The increased availability of digital data and the use of digital mapping techniques gives new meaning to Tyrwhitt's research method. Historic geo-spatial mapping facilitates the research method of surveybefore-plan and allows us to make use of the timeintensive traditional methods of historians and planners, such as archival research, local observation or interviews. Tyrwhitt's research method-based on spatial mapping-can serve as foundation for setting up a research methodology for comparative spatial research. Digitization has increased the number of sources considerably and allows for combining historical data with new scalable maps. Historical maps are not necessarily accurate and interpretation is needed to link them to GIS coordinates. A major challenge for geo-spatial mapping is selecting reliable sources and interpreting them. Tyrwhitt built her research method on the more limited data available to her at the time: historical archives, (air)photos, physical maps, and her own observations. Gathering data from space remained a matter of hopeful thinking. She wrote in 1950: "To obtain a bird's eye view of the ex-

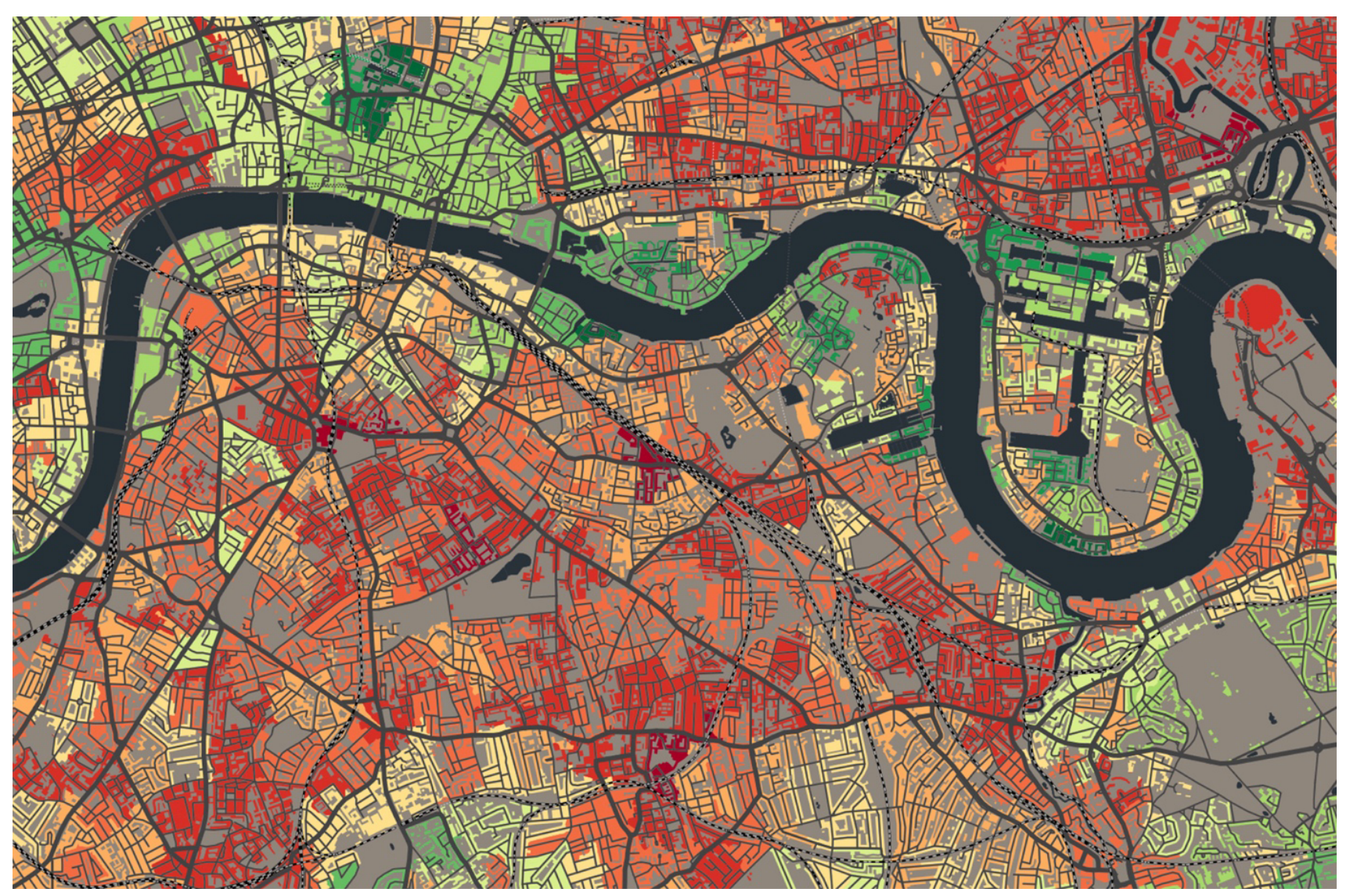

Figure 4. Example of a thematic map of south-east London showing the index of multiple deprivation from 2019 ratings in GIS. Most deprived decile in red, through orange and yellow through to light green and dark green for least deprived decile. Source: Oliver O’Brien \& Consumer Data Research Centre (n.d). C Crown copyright right 2014-06. 
isting pattern of physical conditions, an airplane flight could be made, or aerial photographs studied" (Tyrwhitt, 1950b, p. 149).

The use of GIS allows us to create a palimpsest from the diverse information embedded in historic maps of different provenance and to stitch these maps together using GIS. It also provides us with a unique opportunity to connect spatial maps with other quantitative and qualitative socio-spatial data. As a result, we can gain new insights into historical processes that have shaped the landscape. We can also visualize areas that have received more attention than others: For example, urban areas may have been depicted more often than rural ones. GIS based geo-spatial mapping can even serve as a foundation for the analysis and linkage of representations such as paintings, photographs, or postcards. The opportunities of GIS based geo-spatial mapping can help us overcome one key challenge of historical mapping-that of the choice of scale.

As Nijhuis stressed in his dissertation on GIS-based landscape design research:

The computer and software cannot make sense of data without the expertise of the user. This implies that results of using GIS not only depend on the GIS-skills of the design researcher, but also depends on the research focus (what is researched) and the research methods used (how it is researched), and both in relation to the discipline involved. (Nijhuis, 2015, p. 59)

GIS as a tool makes spatial mapping and overlaying data more powerful. But using historical geo-spatial mapping as a way to study requires multiple steps of decisionmaking. These steps include identifying and mapping the most relevant data, defining the right scales and detail level for the maps and finding and interpreting reliable (historical) sources.

\section{Setting Up a Methodology for Mapping Port City Regions}

To gain an initial sense of how such mapping can function as a gap-finder, we have started to build on existing research and to develop a methodology for comparative historical geo-spatial investigation. We are specifically focusing on port cities because they exemplify complex spatial development, long-term investments, intersecting institutional realms, and overlapping flows of goods, people, and ideas. Port cities have experienced multiple transitions through time and they have historically demonstrated a special capacity for bouncing back after crises. Their traditional resilience can hold lessons for other urban areas (Hein, in press). Port city regions share many of these characteristics with other cities, but their location at the intersection of water and land and their dependence on shipping make them a particular type of space and one that is especially vulnerable. As trade cen- ters, port city regions have long been spaces of human and technological innovation and urban development. As economic and transportation hubs, they are home to large infrastructures, energy storage and production, as well as industrial and trade clusters. For thousands of years and around the globe, people have adapted these spaces to accommodate shipping and to defend against major crises. Historically, such collaborations are a trademark of port cities around the world, their public and private stakeholders displaying great capacity for overcoming challenges.

The next section presents some preliminary ideas about decisions that need to be made concerning the use of historical geo-spatial mapping for port city regions. It identifies challenges and opportunities related to available historical data, choices of time, scale, and decisions regarding data layers. We focus on the long-term development of port regions, from urbanization to present, and include several nation-states. Through geo-spatial mapping we aim to better understand the multiple ways in which urban regions and their institutions operate. We also hope to develop a foundation for planning. To use historical geo-spatial mapping as a 'gap-finder' we need to identify the scale where challenges and opportunities become visible. This scale, however, is one that changes over time and through space. In the context of port cities, it is one that reflects the larger impact of port and city practices and their relation to the region. Each scale has its own reasons for investigation. Some scales have been used more extensively, notably ones that depend on specific institutions. The scales of ports and cities within their administrative territories are often represented. These scales do not show the full area where port activities leave their footprint.

To better demonstrate the potential role of mapping in re-conceptualizing the spatial and institutional dimension of port connections and to identify places of conflict and opportunity, we will focus here on the scale of the port city region. We define region here as a fuzzy territory of port-related flows of goods, people, and ideas that cross institutional boundaries without strong, mutually supportive governance frameworks, legal systems, and planning guidelines (Hein, 2019). Ultimately port networks are global, but to make their impact meaningful on a spatial scale, we have chosen a scale where portrelated functions are concentrated and a scale at which borders between water and land, infrastructures, land use, and institutional borders are visible. Politicians, planners, and researchers often grapple with this particular space. Such a scale helps us better understand how multiscalar markets and global value chains leave their imprint on the spaces of the port and on neighboring urban and rural territories, and it demonstrates that stakeholders in these areas are multiple and pursue different goals and functions.

Using ongoing research by the Chair of the History of Architecture and Urban Planning at TU Delft and the Leiden Delft Erasmus PortCityFutures program as a start- 
ing point, we are proposing to focus on a shared body of water-the North Sea-as the foundation for a comparative research program (Figure 5). This focus allows us to establish and test the first steps towards a methodology for historical and spatial analysis through a comparative investigation of the interactions between port, city, and hinterland in three river-based port city regions around the North Sea: The Nieuwe Waterweg in the Netherlands, the Thames in the UK, and the Elbe in Germany. These port city regions are much larger than the cities situated near the ports of Rotterdam, London, and Hamburg. The area near the Nieuwe Waterweg covers the entire Randstad, including Amsterdam, Rotterdam, The Hague, Zoetermeer, and Utrecht. Together with Bremen and Bremerhaven, Hamburg forms the port city region of Elbe. The port of London has largely moved outside the historic city walls, but the decision-makers have remained in the city, creating a huge port city region. For a close analysis of the three case studies, we collected similar types of historical maps for each of the three cities. We geo-referenced this information and overlaid it with generic data on natural and man-made features and governance patterns.

\subsection{Defining the Right Time and Scale Levels}

Decisions on the selection of a specific scale, time, and perspective have to be made based on careful analysis. The scale of an object of study is important, because the choice of an area larger than the study area supposes the availability of additional data. But any smaller size than that of the smallest detail supposes additional knowledge and data as well (de Jong, 2007). GIS makes it possible to view data on various scale levels, but scale is not only related to the area of study, but also to time. The discussion of different temporalities between port and city is an important one that has been discussed elsewhere (Hein, 2016). Identifying the appropriate time period to represent in a map in relation to space allows us to capture key changes and path dependencies (Figures 6 and 7). We have chosen to start our case study in 1300, when the Hanseatic League helped sustain the urban development of cities around the North Sea. We then use steps of 200 years to capture major social, geo-political, or economic changes, such as the Golden Age, starting in Flanders in the 15th century, shifting to Holland in the 17 th century, and to England in the 18th century. We add

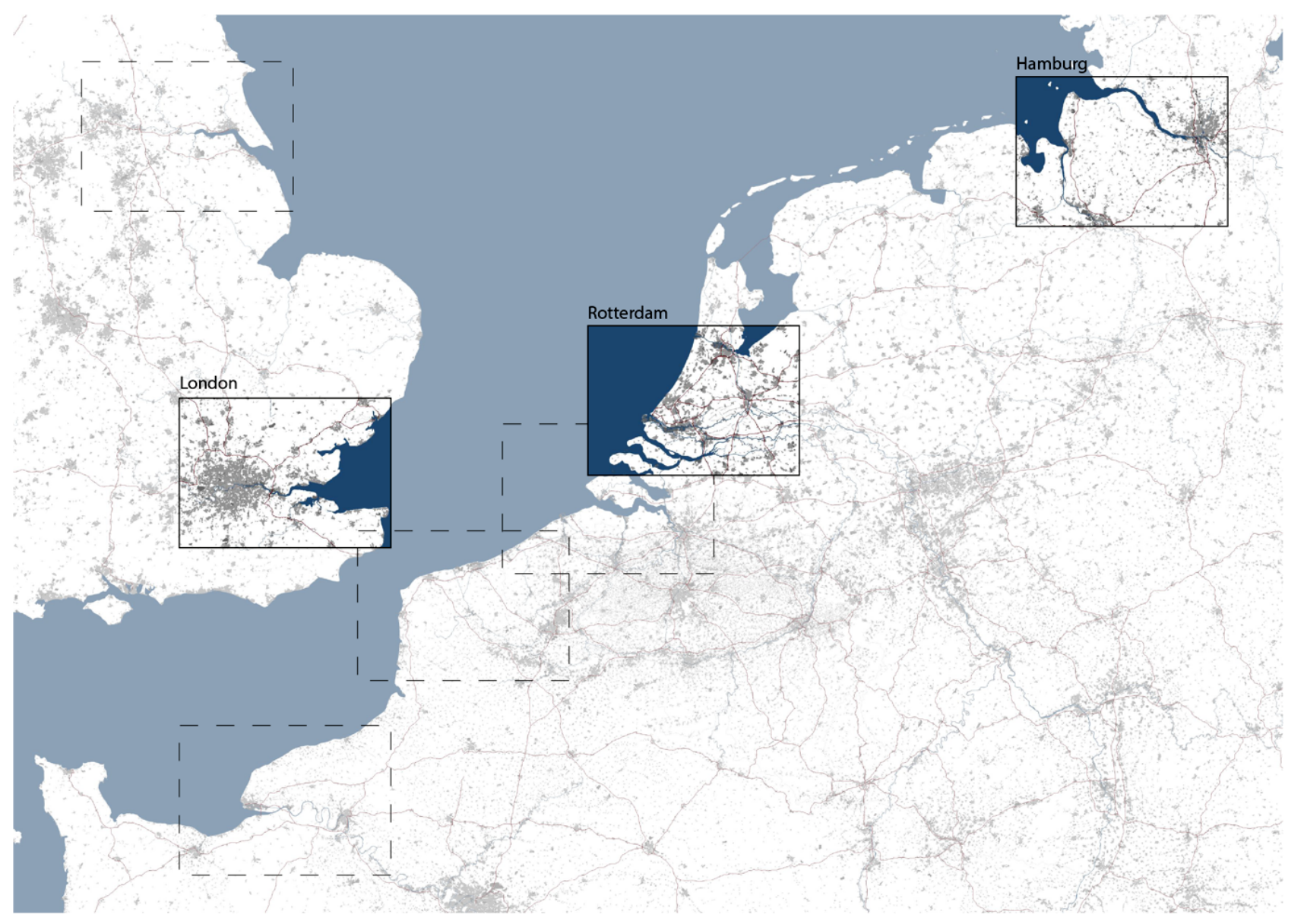

Figure 5. Research areas of the North Sea studied by the Chair of the History of Architecture and Urban Planning, with the case study of London, Hamburg, and Rotterdam highlighted and other potential case studies framed with a dashed line. Map by Yvonne van Mil based on Global Administrative Boundaries (2018), CORINE Land Cover (2016) and EuroGlobalMap (2017). 
more detailed information through steps of 50 years starting with the industrial revolution, when the introduction of new technologies, political systems, new insights on health and legislation on housing and urban planning spurred numerous transitions in cities. These are represented through the years 1850, 1900, 1950, 1990 , and 2020. When we consider a port city as part of a larger system - the region - we need to understand the economic, infrastructural, and social scale on which port cities operate.

At the onset of this process, we need to define the scales for maps that capture the relationship between port cities and their respective region. The relationship between the size of a port, the size of the metropolitan area, and its location in relation to the hinterland has changed over time. A scale of 1:10.000 captures the interaction of ports and cities in medieval cities, but by 1700 we need a scale of 1:25.000 to depict port and city and its immediate hinterland. As a result of urban growth and new defense infrastructure as well as bigger ships and increased shipping, the footprint of the port and the city has increased extensively. The individual locations' responses to these changes may be different, but their scalar impact is similar: all of them grow tremendously. To capture and compare the temporal and spatial dimension of the case studies in the years 1900 and 2020 a much smaller scale, showing a bigger area and less detail, is required. In the case of Rotterdam, Hamburg, and London, it is necessary to analyze them not only at the scale of the city at 1:10 thousand or 1:25 thousand, but also on a regional scale at 1:100 000 and 1:150 000. For a comparative study of the port city regions we need a scale of 1:500 000. Analyzing port, city, and region interaction at all of these scales is important, as it helps us identify relevant gaps.

\subsection{Identifying Relevant Data Layers}

The effectiveness of a map is a result of selectivity, but before selecting or determining data, it is important to acknowledge the purpose of the map in order to select the necessary information. Port city regions are the result of the combined action of both natural and human factors, the local geography, the water system, or the soil conditions on the one hand, and the investment in coastal protection, port and hinterland infrastructure, or in administrative centers on the other. In contrast to natural features, man-made features are more subject to change over time, as they are created and adapted to people's needs. For this reconnaissance we focus on manmade features and we have limited categories of land use to industrial areas, port areas, built-up areas, and densely built-up areas (city center). The density, spatial distribution, and physical characteristics of urban settlements are important drivers of social and environmental changes at multiple scales, and therefore crucial for our research. Infrastructure networks, such as transport networks over water, land, and rail, as well as bridges, dykes and defense systems are another important factor, creating conditions for settlements, economic activities, and mobility. We present the urban morphology in an abstract form, so that the level of detail matches the scale level and the available historical knowledge.

Showing administrative or political boundaries for several nation-states over time is a challenge because each country and each time period uses its own definitions and administrative units. Therefore, it is important to establish shared definitions. To avoid incompatibility issues across incomparable administrative definitions, we adopted hierarchies of categories. We distinguish three categories for political boundaries: Level 1, or the national level, is a recognized independent state (republic or kingdom); level 2, or the regional level, is the intermediate layer (province, region, or county); and level 3, or the local level, is the local government (municipalities or city). Consistent with Tyrwhitt's approach, our research first involves a general reconnaissance, mapping the important physical setting of the port city regions. The estuaries of the Nieuwe Waterweg, the Thames, and the Elbe are the most important element in the region and therefore the general feature or key element on all maps.

\subsection{Finding and Interpreting (Historical) Sources}

One of the biggest challenges in establishing a meaningful methodology for analyzing different geographical regions through time and space involves the availability and quality of (historical) data and sources. The scale of analysis for geo-historical mapping often does not align with the details that are documented. For example, even though information may exist at an urban scale, the same information may be absent at a regional scale or only available at a different time or in a different format, such as written sources. Since we study port regions around the North Sea, it is important to find datasets that cover several nation-states with sufficient spatial resolution to analyze and compare the regions in a consistent and systematic way. Global and continental datasets on transport networks, land use, soil, and elevation are suitable for beginning a systematic comparison. After selecting and preparing these datasets, to obtain the required maps, new data sets must be generated for the earlier periods. From the 19th century onwards, changes in the (urban) landscape can be mapped on the basis of regularly updated national topographic maps, such as Ordnance Survey maps. These topographic maps can serve as a starting point for research farther back in time.

For the period before 1850 , finding reliable sources is much more difficult, especially for the region. Urban areas are often better documented than rural ones. Some historical empires, like Rome or China, produced reliable maps early on, but for most of the cities around the North Sea, reliable information is available only beginning in the 16th century. Early plans that exist are often reconstructions, that is, maps made centuries later, ac- 
cording to ideas of what the city may have looked like. An example is the Plan of London about 1300 by William R. Shepherd in 1926. In the absence of better sources, these reconstructions can be used to obtain an impression of the city around 1300 . The first reliable maps of the area are available from 1500 onwards, such as the city maps of Braun and Hogenberg and Jacob van Deventer.

To get a better understanding of the appropriate time, scale, and perspective to study port city regions, we posit that there are three potential approaches exemplified in Figure 6. The horizontal approach shows different scales for one city in one time period. This scale can allow us, for example, to see how far the port network reached into the hinterland and to compare port city systems such as the Hanseatic League or the British Empire. The vertical approach shows the historical development of a select space at the same scale level. Such an approach shows how what used to be a major part of a multifunctional port city of 1300 has now developed into a revitalized waterfront. Both the horizontal 'scalar' and the vertical 'temporal' approach provide specific aspects to study port city regions over time. To study the interaction between port and city over time and to acknowledge the scalar change through time, we choose the diagonal approach, where scale levels change over time.

The diagonal approach, which we have chosen as a foundation for our research, allows us to make a comparative study of the spatial development of the three case studies to understand how port and city relationships have changed in terms of functionality, size, and location of the port in the city (Figure 7). The overview notably includes infrastructure, land use, and institutional borders.
As a result, we can see that while port and city were always closely spatially and institutionally connected, the relationship between port and city did not always have the same balance in the three cities.

The port was the driver for the emergence of the city of Rotterdam in 1300 . Port activities have led the development of the city and municipal expansion followed the expansion of port territories. The Port of Rotterdam continues to hold a leading role in the development of the region today. Many of the higher-level urban functions linked to the port, such as the location of headquarters, have been 'outsourced' to neighboring cities in the Randstad. Meanwhile, in the case of London, the economic functions of the city have taken the lead in the relation between port and city. After a period of port expansion based on private funding, evidenced first in the growth of the docklands and more recently in the move of port functions to Tilbury, the restraints of the urban context led private players to move first beyond the borders of the city and then those of the larger London region. The case of Hamburg shows a situation where port and city have remained intertwined and have been governed together. As the city grew, so did the port. In 1937, Hamburg incorporated the ports of Altona and Harburg to become a large urban port city region with shipping, port, and administrative capacities (Hein \& Schubert, in press). Based on these maps, we can posit that a city in the vicinity of a port benefits from having control over the port's space and development for environmental, social, and safety reasons. A better understanding of the temporal and scalar development of port city regions from a comparative perspective and of the intersection

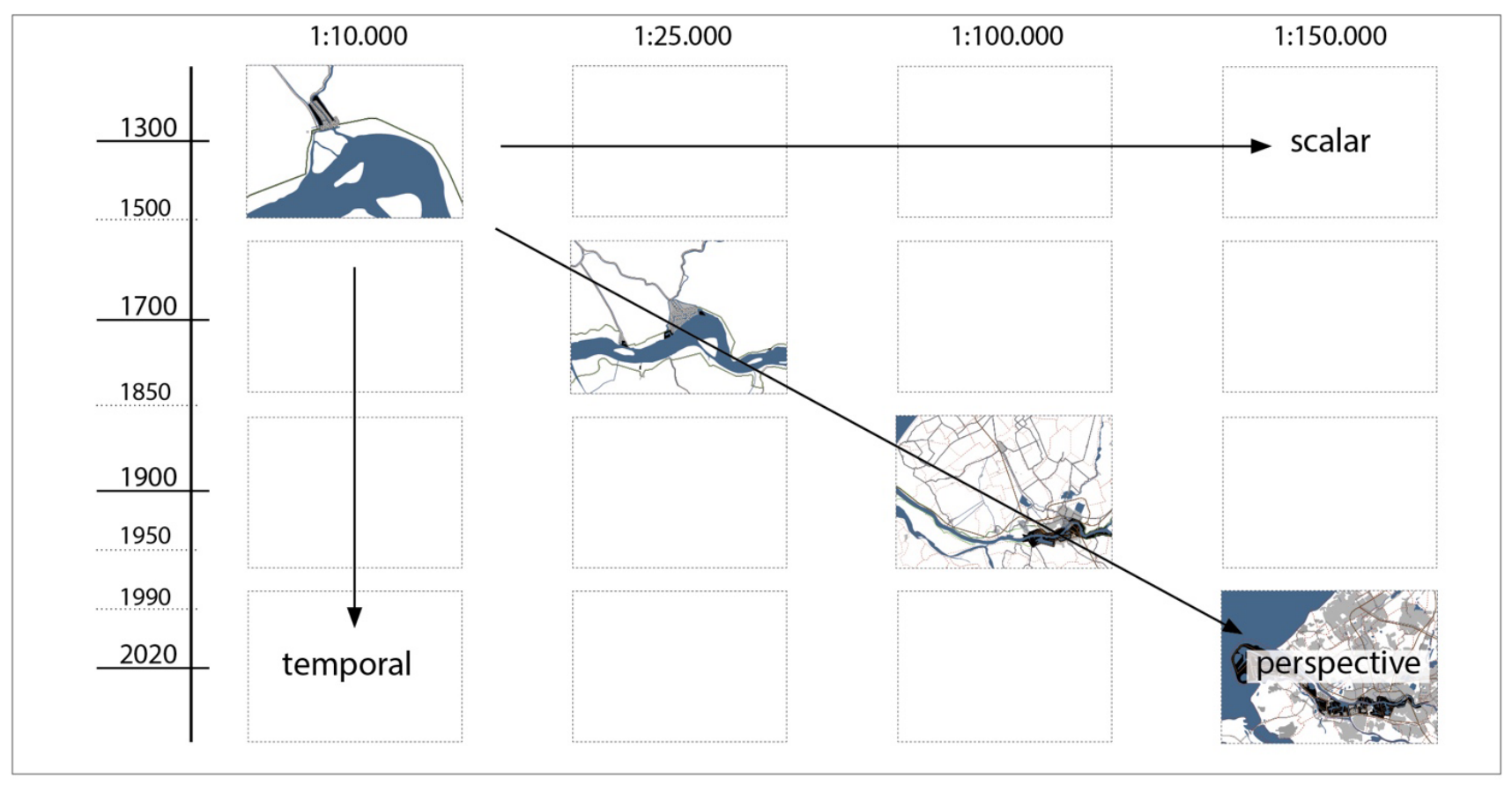

Figure 6. Conceptualization of different approaches to historical geo-spatial mapping and their usefulness for particular disciplinary approaches or questions. Figure by Carola Hein, Yvonne van Mil, Blanka Borbely, and Batuhan Özaltu based on Global Administrative Boundaries (2018) CORINE Land Cover (2016) and EuroGlobalMap (2017). 


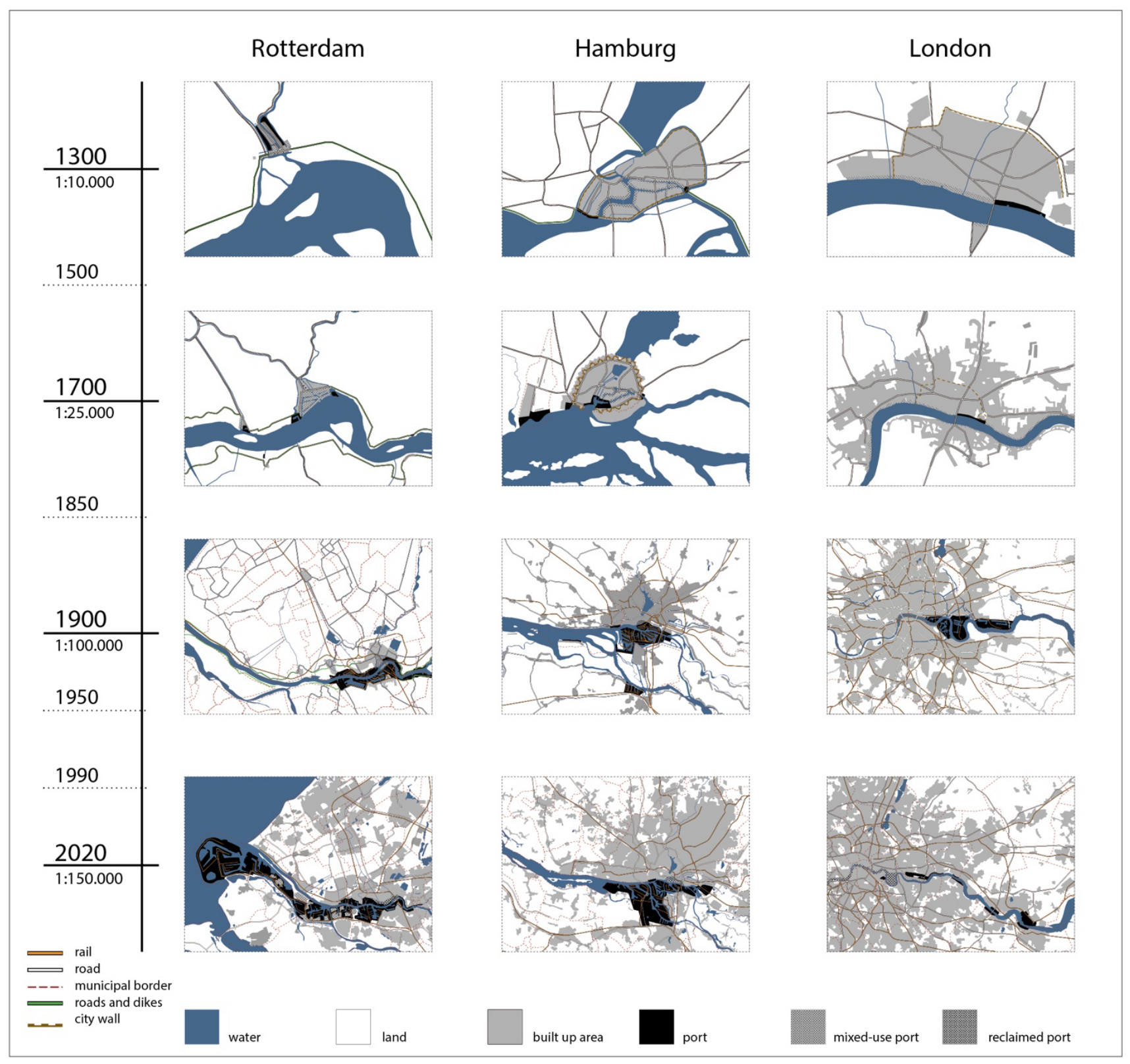

Figure 7. First draft for comparative geo-spatial mapping methodology, with case study of London, Hamburg, and Rotterdam. Figure by Carola Hein, Yvonne van Mil, Blanka Borbely, and Batuhan Özaltun based on Global Administrative Boundaries (2018) CORINE Land Cover (2016) and EuroGlobalMap (2017).

between spatial and social development can inspire better planning for port city regions. For example, one might argue that Rotterdam's striving to increase its standing in the ranking of Maritime Capitals (Späth, 2019) and to catch up with Hamburg would entail a closer collaboration among port and city stakeholders.

\section{Conclusion: Mapping as Gap-Finder}

The reflections on mapping and the role of scale, time, and perspectives presented here provide initial insights into the role of historical geo-spatial research on port city regions from a comparative perspective based on the analysis of complex patterns and multiple scales of spa- tial, social, and cultural transformations. A close analysis of three case study port city regions, the spaces of water and land, of port and city, of built environment and governance, allows us to reflect on the spatial and institutional impact due to the emergence of new technologies, new commodities, larger ships, building technologies, and mobilities. The time periods chosen give insight into the forerunners and followers in their response to these changes. Providing a standardized approach can provide a deeper understanding of how and why contemporary spaces, institutions and cultures emerged, it can also provide a thorough foundation for future-oriented planning. The different scales chosen for our mapping indicate the need to go beyond the scale of the city and to 
study port city regions. Using a temporal or a scalar approach can be attractive to specific disciplines. Historians may benefit from a standardized approach for the thorough study of one place or for the comparative investigation of, for example, historic shipping patterns, ports, and regional development. Planners may benefit from a deep historical analysis of a small site, such as a waterfront, a warehouse district, or office area. The diagonal approach that we have followed allows us to explore the changing port-city relationship in a larger context over time.

Many steps still need to be taken to establish a thorough methodology for comparative longitudinal research on port-city-region relationships. We have started to reflect on the analytical foundation for using historical geo-spatial mapping as a 'gap-finder.' In the long term, such a methodology can help identify opportunities and challenges by exposing spatial and institutional developments that require increased attention from planners. A close analysis of the historic transformation of the built environment (land use, land ownership, infrastructures), the development of institutional structures (municipal boundaries) and the narrative that accompanies them (as embedded in maps and plans) through historical geo-spatial mapping can facilitate the identification of 'gaps,' where spatial, institutional, or cultural opportunities and challenges exist. Such an understanding can provide novel insights into the conditions and complexity of multiple transitions and provide a better foundation for future design.

\section{Acknowledgments}

We are grateful for excellent feedback provided by anonymous reviewers.

\section{Conflict of Interests}

The authors declare no conflict of interests.

\section{References}

Andrade, M. J., Costa, J. P., \& Blasco López, J. (2020). 3DPortCityMeasure: Methodology for the comparative study of good practices in port-city integration. Sustainability, 12(3). https://doi.org/10.3390/ su12030880

Batey, P. (2018). The history of planning methodology. In C. Hein (Ed.), The Routledge handbook of planning history (pp. 46-59). London and New York, NY: Routledge.

Bellin, J. N. (1764). Plan de Roterdam et environs [Map of Rotterdam and surroundings]. [Chart map]. David Rumsey Historical Map Collection. Retrieved from https://www.davidrumsey.com/luna/servlet/detail/ RUMSEY 8 1 233391 5509822:Plan-de-Roterdamet-environs?sort=pub_list_no_initialsort\%2Cpub_ date\%2Cpub_list_no\%2Cseries_no\&qvq=q:
Plan\%20de\%20Rotterdam\%20et\%20environs;sort: pub_list_no_initialsort\%2Cpub_date\%2Cpub_list_ no\%2Cseries_no;lc:RUMSEY 8 1\&mi=0\&trs=1

Bodenhamer, D. J., Harris, T. M., \& Corrigan, J. (2015). Deep maps and spatial narratives. Bloomington, IN: Indiana University Press.

Booth, C. (1898). Inquiry into the life and labour of the people in London. London: Williams and Norgate. Retrieved from https://booth.Ise.ac.uk/learn-more/ download-maps

Copernicus. (2016). CORINE Land Cover. Version 18.5. Copernicus. Retrieved from https://land.copernicus. eu/pan-european/corine-land-cover/lcc-2006-2012/ view

de Jong, T. M. (2007). Context analysis. Rotterdam: 010 publishers.

Denis, L., \& Pasquier, J. J. (1765). Ille. Feuille du plan de Paris. IVe. Feuille du plan de Paris [III. Sheet of the Paris map. 4th. Paris map sheet]. [Chart map]. David Rumsey Historical Map Collection. Retrieved from https://www.davidrumsey.com/luna/ servlet/detail/RUMSEY 8 1 314486 90083426: IIle--Feuille-du-plan-de-Paris--IVe?sort=pub_ list_no_initialsort\%2Cpub_date\%2Cpub_list_no\% 2Cseries_no\&qvq=q:Feuille\%20du\%20plan\%20de\% 20Paris.\%20IVe.\%20Feuille\%20du\%20plan\%20de\% 20Paris.\%20Paris;sort:pub_list_no_initialsort\% 2Cpub_date\%2Cpub_list_no\%2Cseries_no;lc: RUMSEY 8 1\&mi=0\&trs=2

Eurogeographics. (2017). EuroGlobalMap. Version 10.0. Eurogeographics. Retrieved from https:// eurogeographics.org/maps-for-europe/open-data

Fuechsel, C. F. (n.d.). Map-Cartography. In Encyclopedia Britannica. Retrieved from https://www.britannica. com/science/map/Modern-mapmaking-techniques

Global Administrative Boundaries. (2018). GADM data. Version 36-2018. Global Administrative Boundaries. Retrieved from https://gadm.org/download_world. html

Gregory, I. N., \& Geddes, A. (2014). Introduction: From historical GIS to spatial humanities: Deepening Scholarship and broadening technology. In I. N. Gregory \& A. Geddes (Eds.), Toward spatial humanities. Historical GIS \& spatial history (pp. ix-xix). Bloomington, IN: Indiana University Press.

Grimoard, P. H., \& de Beaurain, J. (1672). Carte de la Hollande et d'une Partie des Etats Voisins: Volume 2. [Map of Holland and a part of the neighboring states: Volume 2]. [Chart map]. David Rumsey Historical Map Collection. Retrieved from https://www. davidrumsey.com/luna/servlet/detail/RUMSEY 8 1 301139 90072119:Volume-2-Carte-de-laHollande-et-d?sort=pub_list_no_initialsort\%2Cpub_ date\%2Cpub_list_no\%2Cseries_no\&qvq=q:.\%20 Carte\%20de\%20la\%20Hollande\%20et\%20d\%27une \%20partie\%20des\%20Etats\%20voisins;sort:pub_list_ no_initialsort\%2Cpub_date\%2Cpub_list_no\% 2Cseries_no;|lc:RUMSEY 8 1\&mi=0\&trs $=1$ 
Guo, J., Qin, Y., Du, X., \& Han, Z. (2020). Dynamic measurements and mechanisms of coastal portcity relationships based on the $\mathrm{DCl}$ model: Empirical evidence from China. Cities, 96. https://doi.org/ 10.1016/j.cities.2019.102440

Hein, C. (2016). Port cities and urban waterfronts: How localized planning ignores water as a connector. Wiley Interdisciplinary Reviews: Water, 3(3), 419-438. https://doi.org/10.1002/wat2.1141

Hein, C. (2018). The what, why, and how of planning history. In C. Hein (Ed.), The Routledge handbook of planning history (pp. 1-10). London and New York, NY: Routledge.

Hein, C. (2019). The port cityscape: Spatial and institutional approaches to port city relationships. PortusPlus, 8, 1-8. Retrieved from https://portusplus.org/ index.php/pp/article/view/190

Hein, C., \& Schubert, D. (in press). Resilience and path dependence: A comparative study of the port cities of London, Hamburg and Philadelphia. Journal of Urban History.

Hein, C., \& van Mil, Y. (2019). Towards a comparative spatial analysis for port city regions based on historical geo-spatial mapping. PortusPlus, 8, 1-18. Retrieved from https://portusplus.org/index.php/pp/ article/view/189/186

Hillier, A. (2010). Invitation to mapping: How GIS can facilitate new discoveries in urban and planning history. Journal of Planning History, 9(2), 122-134. https:// doi.org/10.1177/1538513210366964

Meyer, H., \& Nijhuis, S. (2014). Urbanized deltas in transition. Amsterdam: Techne Press.

Meyer, J. (1852). Vergleichende Uebersicht der bedeutendsten Stromlängen [Comparative overview of the most important river lengths]. [Chart map]. David Rumsey Historical Map Collection. Retrieved from https://www.davidrumsey.com/luna/ servlet/detail/RUMSEY 8 1 305120 90075527: Vergleichende-Ubersicht-der-bedeute?sort=pub_ list_no_initialsort\%2Cpub_date\%2Cpub_list_no\% 2Cseries_no\&qvq=w4s:/when\%2F1852\%2F;q: Meyer\%27s\%20Zeitungs\%20Atlas;sort:pub_list_no_ initialsort\%2Cpub_date\%2Cpub_list_no\%2Cseries_ no;lc:RUMSEY 8 1\&mi=112\&trs=156

Monios, J., Bergqvist, R., \& Woxenius, J. (2018). Portcentric cities: The role of freight distribution in defining the port-city relationship. Journal of Transport Geography, 66, 53-64. https://doi.org/10.1016/ j.jtrangeo.2017.11.012

Monmonier, M. (2014). How to lie with maps. Chicago, IL: University of Chicago Press. (Original work published 1996)

Nijhuis, S. (2015). GIS-based landscape design research: Stourhead landscape garden as a case study. Delft: $\mathrm{A}+\mathrm{BE} \mid$ Architecture and the Built Environment.

O'Brien, O., \& Consumer Data Research Centre. (n.d.). Index of multiple deprivation 2019. CDRC Maps. Retrieved from https://maps.cdrc.ac.uk/\#/
geodemographics/imde2019/default/BTTTFFT/10/ $-0.1500 / 51.5200$

Olazabal, M., Ruiz de Gopegui, M., Tompkins, E. L., Venner, K., \& Smith, R. (2019). A cross-scale worldwide analysis of coastal adaptation planning. Environmental Research Letters, 14(12). https://doi.org/ 10.1088/1748-9326/ab5532

Renes, H. (2016). Gebruik van kaarten voor historische onderzoek [Use of maps for historical research]. In M. Hameleers, M. Carnier, P. Alkhoven, \& R. Kruk (Eds.), Cartografie Visie op de kaart [Cartography vision on the map] (Vol. 15, pp. 153-176). The Hague: Stichting Archiefpublicaties.

Robinson, A. H. (1982). Early thematic mapping in the history of cartography. London and Chicago, IL: University of Chicago Press.

Schipper, C. A., Vreugdenhil, H., \& de Jong, M. P. C. (2017). A sustainability assessment of ports and portcity plans: Comparing ambitions with achievements. Transportation Research Part D: Transport and Environment, 57, 84-111. https://doi.org/10.1016/j.trd. 2017.08.017

Sert, J. L. (1944). Can our cities survive? An ABC of urban problems, their analysis, their solutions. Cambridge, MA: Harvard University Press.

Shoshkes, E. (2006). Jaqueline Tyrwhitt: A founding mother of modern urban design. Planning Perspectives, 21(2), 179-197. https://doi.org/10.1080/ 02665430600555339

Shoshkes, E. (2016). Jaqueline Tyrwhitt translates Patrick Geddes for post-World War Two planning. Landscape and Urban Planning, 166, 15-24.

Späth, N. (2019). Leading maritime capitals of the world report 2019: Singapore still on top. DNV GL. Retrieved from https://www.dnvgl.com/news/ leading-maritime-capitals-of-the-world-report2019-singapore-still-on-top-145477\#

Teixeira de Mattos, I. (1866). Map showing the spread of cholera and the number of deaths from this disease in each of the 50 neighborhoods of Amsterdam. Allard Pierson Handbibliotheek (OTM: HB-KZL 105.19.03). Allard Pierson, University of Amsterdam, Amsterdam.

Tyrwhitt, J. (1950a). Society and environment. A historical view. In APRR (Ed.), Town and country planning textbook (pp. 96-145). London: The Architectural Press.

Tyrwhitt, J. (1950b). Surveys for planning. In APRR (Ed.), Town and country planning textbook (pp. 146-196). London: The Architectural Press.

Vaughan, L. (2018). Mapping society: The spatial dimensions of social cartography. London: UCL Press.

Viele, E. L. (1865). Sanitary \& topographical map of the city and island of New York. New York, NY: Ferd. Mayer \& Co.

Whittle, J. (1950). The preparation of planning maps: sources, notations and methods of reproduction. In APRR (Ed.), Town and country planning textbook (pp. 540-559). London: The Architectural Press. 
Wilkinson, R. (1809). The world from the discoveries \& observations made in the latest voyages \& travels. [Chart map]. David Rumsey Historical Map Collection. Retrieved from https://www.davidrumsey.com/ luna/servlet/detail/RUMSEY 8 1 241677 5512696:
World-?sort=pub_list_no_initialsort\%2Cpub_date\% 2Cpub_list_no\%2Cseries_no\&qvq=q:Wilkinson\%27s \%20general\%20atlas\%20of\%20the\%20world;sort: pub_list_no_initialsort\%2Cpub_date\%2Cpub_list no\%2Cseries_no;lc:RUMSEY 8 $1 \& \mathrm{mi}=5 \& \operatorname{trs}=143$

\section{About the Authors}

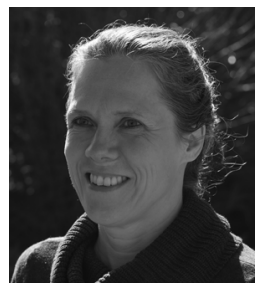

Carola Hein is Professor of History of Architecture and Urban Planning at TU Delft. She has published widely and received a Guggenheim and an Alexander von Humboldt fellowship as well as other major grants. Her books include Adaptive Strategies for Water Heritage (2019), The Routledge Planning History Handbook (2017), Uzō Nishiyama, Reflections on Urban, Regional and National Space (2017), Port Cities (2011), The Capital of Europe (2004), Rebuilding Urban Japan after 1945 (2003), and Cities, Autonomy and Decentralisation in Japan (2006), and Hauptstadt Berlin 1957-58 (1991).

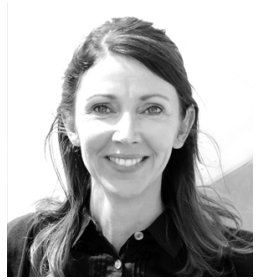

Yvonne van Mil studied Architecture at TU Delft (MSc), where she specialized in the public realm in port cities. After graduating, she pursued her interests as an independent researcher and cartographer, affiliated with TU Delft. Her research topics includes urban and spatial planning in the 19th and 20th century, focusing specifically on regional history and geo-spatial mapping. She was co- author of several books including Driven by Steel. From Hoogovens to Tata Steel 1918-2018 (2018) and contributed chapters to the Atlas of the Dutch Urban Landscape (2014). 